\title{
Diagnosis and management of chronic obstructive pulmonary disease in Serbia: an expert group position statement
}

This article was published in the following Dove Press journal: International Journal of Chronic Obstructive Pulmonary Disease

\author{
Marija Vukoja ${ }^{1,2}$ \\ Ivan Kopitovic ${ }^{1,2}$ \\ Zorica Lazic ${ }^{3,4}$ \\ Branislava Milenkovic ${ }^{5,6}$ \\ Ivana Stankovic ${ }^{7,8}$ \\ Biljana Zvezdin ${ }^{1,2}$
}

Aleksandra Dudvarski Ilic ${ }^{5,6}$

Ivan Cekerevac ${ }^{3,4}$

Miodrag Vukcevic ${ }^{6,9}$

Vladimir Zugic ${ }^{5,6}$

Sanja Hromis ${ }^{1,2}$

'The Institute for Pulmonary Diseases of Vojvodina, Sremska Kamenica, Serbia;

${ }^{2}$ Faculty of Medicine, University of Novi Sad, Novi Sad, Serbia; ${ }^{3}$ Clinic for

Pulmonology, Clinical Centre Kragujevac, Kragujevac, Serbia; ${ }^{4}$ Faculty of Medicine, University of Kragujevac, Kragujevac, Serbia; ${ }^{5}$ Clinic for Pulmonology, Clinical

Centre of Serbia, Belgrade, Serbia;

${ }^{6}$ Faculty of Medicine, University of Belgrade, Belgrade, Serbia; ${ }^{7}$ Clinic for Lung Diseases, Clinical Centre of Nis, Nis, Serbia; ${ }^{8}$ Faculty of Medicine, University of Nis, Nis, Serbia; ${ }^{9}$ Clinical Hospital Centre Zemun, Belgrade, Serbia

Correspondence: Marija Vukoja Centre for Pathophysiology of Breathing and Sleep Medicine, The Institute for Pulmonary Diseases of Vojvodina, Put dr Goldmana 4 Street, Sremska Kamenica 21204 , Serbia

Tel +38I 2I 4805205

Email marija.vukoja@mf.uns.ac.rs

\begin{abstract}
In recent years, several national chronic obstructive pulmonary disease (COPD) guidelines have been issued. In Serbia, the burden of COPD is high and most of the patients are diagnosed at late stages. Global Initiative for Chronic Obstructive Lung Disease (GOLD) strategy is poorly implemented in real-life practice, as many patients are still prescribed inhaled corticosteroids (ICS)-containing regimens and slow-release theophylline. In this document, we propose an algorithm for treating COPD patients in Serbia based on national experts' opinion, taking into account global recommendations and recent findings from clinical trials that are tailored according to local needs. We identified four major components of COPD treatment based on country specifics: active case finding and early diagnosis in high-risk population, therapeutic algorithm for initiation and escalation of therapy that is simple and easy to use in real-life practice, de-escalation of ICS in low-risk non-exacerbators, and individual choice of inhaler device based on patients' ability and preferences. With this approach we aim to facilitate implementation of the recommendation, initiate the treatment in early stages, improve cost-effectiveness, reduce possible side effects, and ensure efficient treatment.
\end{abstract}

Keywords: COPD, treatment, guidelines

\section{Introduction}

With an estimated prevalence of $12 \%$ and 3 million deaths annually, chronic obstructive pulmonary disease (COPD) is a major health problem worldwide. ${ }^{1,2}$ In Serbia, self-reported prevalence of COPD is $5 \%$ in females and $3.7 \%$ in males. ${ }^{3}$ This is a large underestimation, as active case finding in symptomatic high-risk Serbian population showed a prevalence of $22 \%$ in general practice ${ }^{4}$ and similar results were obtained using patient questionnaires. ${ }^{5}$ According to the recent Phenotypes of COPD in Central and Eastern Europe (POPE) study, non-exacerbators are the most frequent COPD phenotype in Serbia. ${ }^{6}$ Global Initiative for Chronic Obstructive Lung Disease (GOLD) guidelines are poorly reflected in reallife practice, as more than half of these patients receive inhaled corticosteroids (ICS) and many of them receive slow-release theophylline. ${ }^{6,7}$ Although intended to be global, multiple barriers preclude implementation of GOLD strategy worldwide, including availability of drugs and diagnostic procedures and country-specific regulatory affairs. This has been further hampered by the increasing complexity of COPD phenotypes and algorithms that are difficult to follow in busy outpatient 
settings. The need for context-specific implementation and tailoring guidelines according to local needs have been increasingly recognized and resulted in several national guidelines and position statements in the last years including Russian, ${ }^{8}$ Spanish, ${ }^{9}$ Czech, ${ }^{10}$ Saudi Arabian, ${ }^{11}$ Canadian, ${ }^{12}$ and French. ${ }^{13}$ In this paper, we present recommendations for treatment of COPD in Serbia.

\section{Methodology}

The development of these recommendations was based on national COPD experts' opinions and feedback from a panel of pulmonologists. First, a field survey on current clinical practice was performed using available epidemiological studies from the region and data from the national registry. ${ }^{4,5,7,14}$ Second, an extensive review of the literature including GOLD strategy and the guidelines from various national societies was performed for the period of the last 6 years since the last national guideline was published. ${ }^{15}$ Only the medications available in Serbia were discussed. Three rounds of expert meetings (two face-toface meetings and one video conference) were held during the following 6-month period to discuss treatment algorithms. Both the scientific rationale and local applicability of the algorithms were evaluated. Disagreements were resolved by consensus. In the absence of consensus, a final decision was made by a simple majority rule. We presented experts' opinion statement rather than a formal guideline, as the primary aim was to develop locally applicable recommendations and there was no formal grading of the evidence.

We identified four major components for treating COPD patients based on country specifics: 1) active case finding and early diagnosis in high-risk population, 2) therapeutic algorithm for initiation and escalation of therapy that is simple and easy to use in a real-life situation, 3) de-escalation of ICS in low-risk non-exacerbators, and 4) individual choice of inhaler device based on patients' ability and preferences.

\section{Recommendations}

\section{Active case finding}

We recommend active case finding in patients $>40$ years of age with 10 pack/years smoking who have symptoms of cough, wheezing or exertional dyspnea. The diagnosis should be made if $\mathrm{FEV}_{1} / \mathrm{FVC}$ is $<70 \%$ measured 15 minutes after four puffs of $100 \mathrm{mcg}$ salbutamol. In centers that use lower limit of normal (LLN), the $\mathrm{FEV}_{1} / \mathrm{VC}<\mathrm{LLN}$ threshold should be used.

The prevalence of COPD in Serbia is underestimated. ${ }^{3-5}$ High smoking prevalence, exposure to biomass fuels, and poor air quality all increase the risk of COPD in Serbia. According to a health examinations survey, despite enforcement of tobacco control, $35 \%$ of the adult population are smokers. ${ }^{16}$ Active case finding enables timely diagnosis and offers a window of opportunity for early intervention and prevention of functional decline. High-quality spirometry should be performed according to the American Thoracic Society-European Respiratory Society (ATS/ERS) criteria and staff performing spirometry adequately trained. ${ }^{17,18}$ National spirometry courses endorsed by the ERS have been available yearly since 2014 . When reported, a postbronchodilator value of $\mathrm{FEV}_{1}$ (postbd $\mathrm{FEV}_{1}$ ) should be used. ${ }^{19}$

\section{Algorithm of initiating and escalating COPD treatment}

Non-pharmacological treatment

All patients should receive non-pharmacological measures including smoking cessation counseling, vaccination, and rehabilitation.

Many cases of COPD are preventable by avoidance or early cessation of smoking. ${ }^{20}$ Influenza vaccination reduces lower respiratory tract infections, COPD exacerbations, and mortality in COPD patients. ${ }^{21,22}$ Pneumococcal vaccine reduces pneumococcal disease in patients $>65$ years old and younger patients with $\mathrm{FEV}_{1}<40 \%$ or comorbidities. ${ }^{23}$ Pulmonary rehabilitation improves dyspnea and exercise tolerance. ${ }^{24}$ Non-pharmacological treatments have all been shown to be cost-effective in high-income countries ${ }^{22,25,26}$ and may be even more relevant in resource-limited settings. ${ }^{27}$ Special consideration should be given to smoking cessation counseling and vaccination due to high smoking prevalence $^{16}$ and low vaccination rates in Serbia. ${ }^{28}$ As availability of hospital-based rehabilitation is limited, home-based rehabilitation programs should be offered, especially in patients with dyspnea.

\section{Pharmacological treatment}

We divided patients into low- and high-risk patients based on dyspnea and lung function. The initial pharmacological treatment and escalation of therapy algorithm is presented in Figure 1. In all patients, in addition to the recommended treatment, short-acting bronchodilators should be prescribed as a "reliever" medication. 


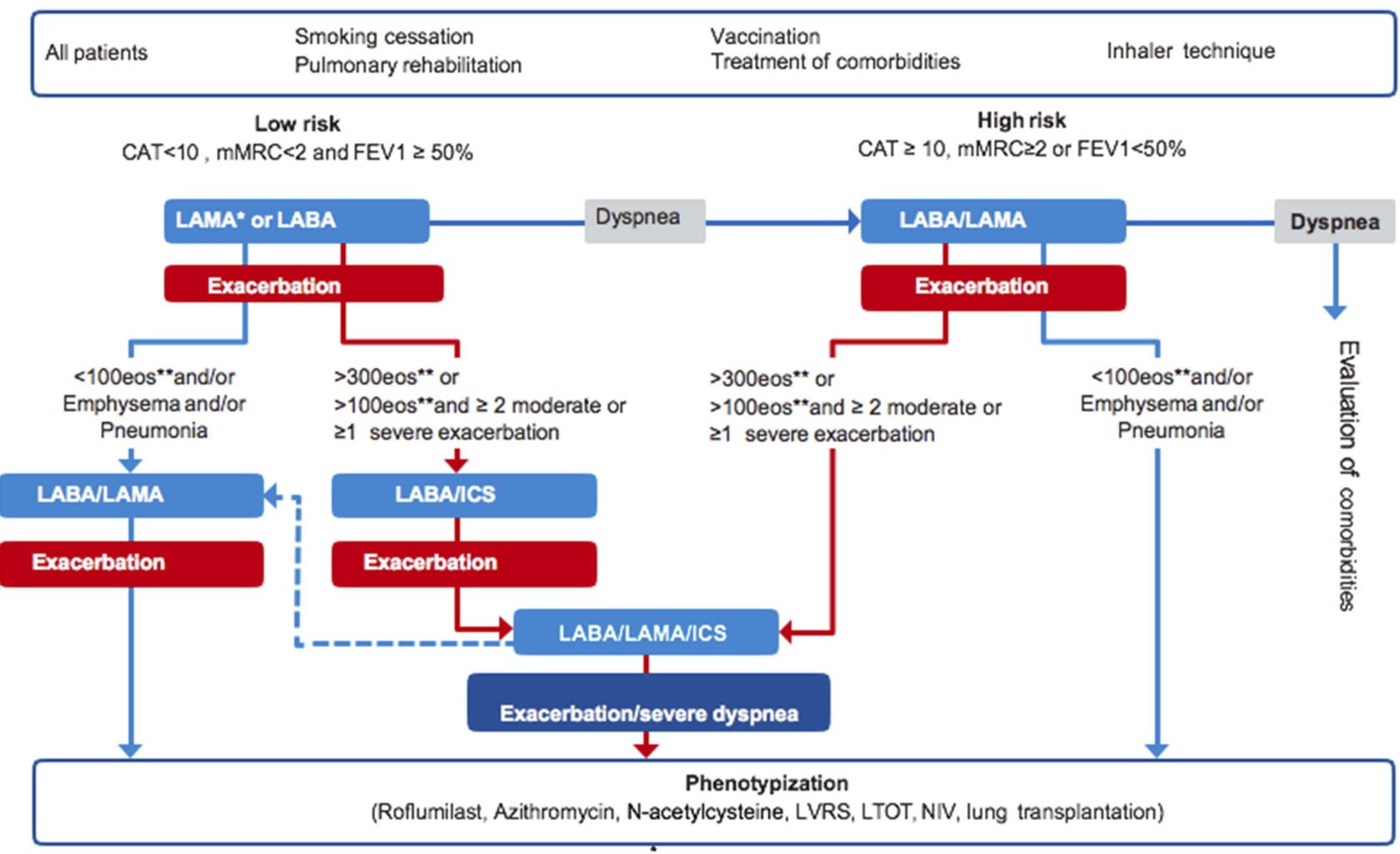

Figure I Algorithm for initiation and escalation of therapy. *In case of presentation with exacerbation LAMA is preferred. **Eosinophils should be measured at the time of diagnosis and at least on one more separate occasion.

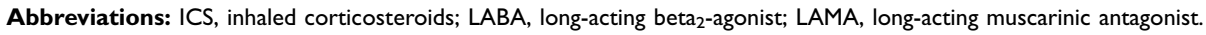

Low-risk patients $(\mathrm{CAT}<10$ or $\mathrm{mMRC}<2$ and postbdFEV $1 \geq 50 \%$ ): we recommend initiating treatment with long-acting bronchodilator, long-acting muscarinic antagonist (LAMA) or long-acting beta ${ }_{2}$-agonist (LABA).

We recommend long-acting bronchodilator as initial treatment due to progressive course of the disease. We do not recommend starting treatment with short-acting bronchodilators on "as needed" basis as in a recent study of mild COPD patients, administration of LAMA was associated with lung function improvement and reduction of exacerbations compared to placebo. ${ }^{29}$ If patient presents with exacerbation we recommend starting treatment with LAMA, as two clinical trials demonstrated superiority of LAMA over LABA in reducing exacerbations. ${ }^{30,31}$

We recommend early phenotypization using medical history and blood eosinophil count. All patients should be carefully evaluated for past medical history of asthma, presence of atopy or eosinophilia and if positive, asthma-COPD overlap (ACO) should be considered (Figure 2). ${ }^{32,33}$ Blood eosinophil count is a simple biomarker of eosinophilic airway inflammation that identifies patients at increased risk of exacerbations and predicts efficacy of ICS. $^{34}$ Eosinophils should be measured at the time of diagnosis and at least at one more occasion, due to temporal variation in the biomarker. ${ }^{35,36}$

\section{Escalation of therapy in low-risk patients}

Dyspnea: if no response to treatment in terms of dyspnea ( $C A T \geq 10$, mMRC $\geq 2$ ), we recommend escalation of therapy to dual bronchodilators (LAMA/LABA). If dyspnea progresses despite optimal bronchodilatation, we recommend careful assessment of comorbidities, especially cardiovascular diseases, obesity, sleep apnea, anxiety, depression, and anemia.

Exacerbations: we recommend escalating from longacting bronchodilator to LABA/LAMA in patients with eosinophil count $<100 / \mu \mathrm{L}$. If further exacerbations occur in patients on LABA/LAMA, we recommend detailed investigation and treatment according to specific phenotype. We recommend escalating from long-acting bronchodilator to LABA/ICS in patients with eosinophil count $>300 / \mu \mathrm{L}$ or eosinophil count $>100 / \mu \mathrm{L}$ and $\geq 2$ moderate or one severe exacerbation in the previous year. If further exacerbations occur in patients on LABA/ICS, we recommend escalation to triple therapy. 


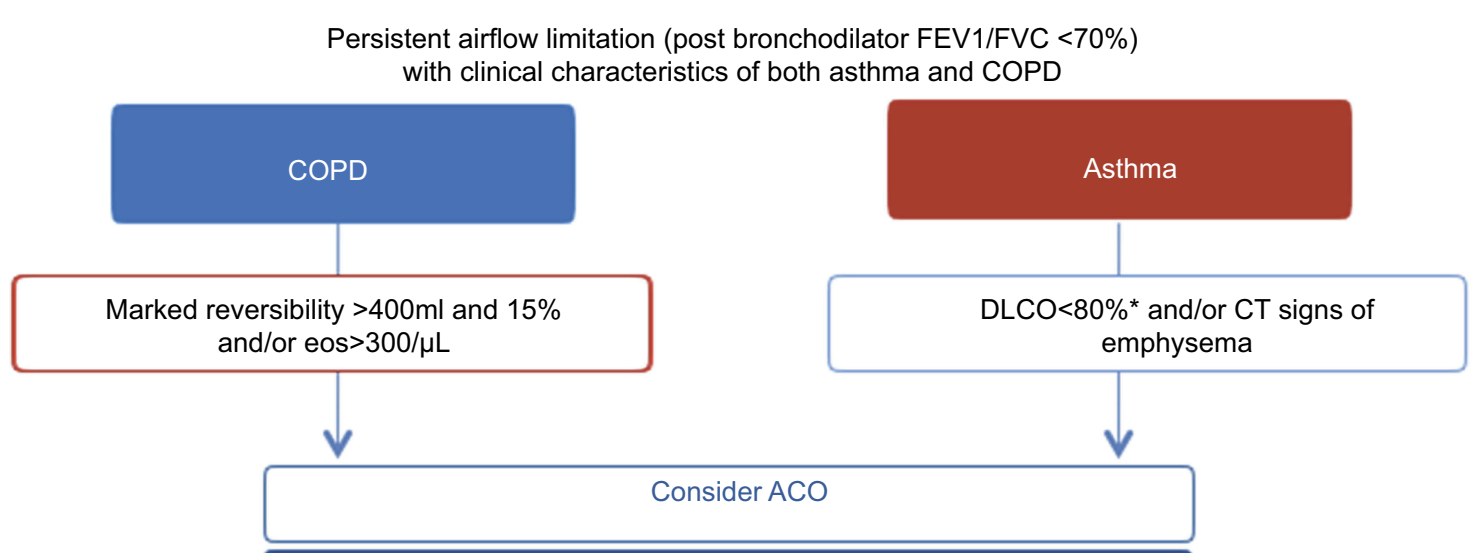

ICS (low to moderate dose)+ LABA and/or LAMA

Figure 2 Algorithm for diagnosis and initial treatment of asthma-COPD overlap (ACO). *Outside of exacerbations. Abbreviations: LABA, long-acting beta 2 -agonist; LAMA, long-acting muscarinic antagonist.

Dual bronchodilation treatment has constantly shown improvement in $\mathrm{FEV}_{1}$ and patient-reported outcomes compared to monotherapy, without increasing the risk of side effects. ${ }^{37}$ In case of persistent dyspnea, the patient should be referred to a specialized center for assessment of comorbidities, as such evaluation is generally unavailable. ${ }^{19,38,39}$

About one quarter of COPD patients have persistently low eosinophil count. ${ }^{36}$ These patients have increased risk of pneumonia ${ }^{40}$ and respond poorly to ICS. ${ }^{34}$ Escalation to LABA/LAMA should also be considered in patients with pneumonia or emphysema. ${ }^{41}$ In patients on LABA/LAMA with low eosinophil count who experience exacerbation, we recommend additional phenotype-based treatment with roflumilast or azithromycin or high-dose $\mathrm{N}$-acetylcysteine.

There is robust evidence that ICS are effective in COPD patients with high eosinophil count. ${ }^{34,41-44}$ Although the specific cut-off has been a matter of debate, the efficacy starts to be apparent when eosinophil count is over $100 / \mu \mathrm{L}$ and increases with the number of eosinophils. ${ }^{34}$ The effect of ICS in reducing exacerbations is most evident in patients with $>300 / \mu \mathrm{L}$ eosinophils. ${ }^{45}$ The same cut-off has constantly been associated with superiority of an ICS containing treatment when considering ICS withdrawal. ${ }^{42,46}$ As the number of exacerbations is the strongest predictor of future exacerbations, ${ }^{47}$ combining number of exacerbations and eosinophil count can identify patients at higher risk of exacerbations. ${ }^{19,48}$ In patients with exacerbations and eosinophil count $>150 / \mu \mathrm{L}$, the annual rate of exacerbations was reduced with ICS-containing treatments. Higher thresholds of eosinophils are associated with ICS effectiveness in smokers. $^{49}$
In patients on LABA/ICS who experience further exacerbations, we recommend escalation to triple therapy (LABA/LAMA/ICS). ${ }^{49,50}$ If further dyspnea, exacerbations or complications of ICS therapy occur, we recommend detailed investigation and therapy adjustment according to phenotypes.

High-risk patients $\quad(\mathrm{CAT} \geq 10$ or $\quad \mathrm{mMRC} \geq 2 \quad \mathrm{OR}$ postbdFEV $\mathrm{F}_{1}<50 \%$ ): we recommend initiating treatment in high-risk patients with LABA/LAMA combination.

Dual bronchodilators have persistently shown improvement in lung function, dyspnea, and quality of life, and a tendency to decrease number of exacerbations compared to single bronchodilators without significant side effects. ${ }^{37}$ Although the effects are modest, they are consistent and we believe that dual therapy should be initiated in symptomatic patients rather than waiting for patients to experience severe breathlessness. Furthermore, the observed effect may have an impact on patient level, especially in more severe, high-risk patients where even modest improvements can significantly affect patients' lives. ${ }^{51}$ LABA/LAMA also reduce lung hyperinflation, improve left ventricular filling, and exercise capacity. ${ }^{52,53}$

\section{Escalation of the therapy in high-risk patients}

Dyspnea: in patients who continue to have symptoms despite dual bronchodilators, we recommend detailed investigation and treatment of comorbidities.Exacerbations: in patients with eosinophils $<100 / \mu \mathrm{L}$ we recommend additional evaluation and treatment according to phenotypes. We recommend escalating to LAMA/LABA/ICS in patients with eosinophil count $>300 / \mu \mathrm{L}$ or eosinophil count 
$>100 / \mu \mathrm{L}$ and $\geq 2$ moderate or one severe exacerbation in the previous year.

Two large clinical trials recently demonstrated superiority of triple therapy compared to dual bronchodilators in exacerbating patients. ${ }^{41,49}$ The TRIBUTE trial included high-risk $\left(\mathrm{FEV}_{1}<50 \%\right)$ symptomatic (CAT $\left.\geq 10\right)$ patients with at least one moderate exacerbation, ${ }^{41}$ and the IMPACT trial included symptomatic patients with $\mathrm{FEV}_{1}<50 \%$ and at least one moderate exacerbation or with $\mathrm{FEV}_{1} \geq 50 \%$ and at least two moderate or one severe exacerbation. In a subset analysis of these trials the benefits were more pronounced in patients with high eosinophil count. ${ }^{49}$

\section{Other treatments according to specific phenotype} In patients who continue to exacerbate or have persistent dyspnea despite optimal treatment, additional investigations should be performed and treatment based on individual basis.

In patients who continue to exacerbate, despite being treated with LABA/LAMA/ICS or LABA/LAMA with low eosinophil count, treatment with roflumilast or antibiotics or high-dose $\mathrm{N}$-acetylcysteine should be considered.

\section{Roflumilast}

Roflumilast should be considered in patients with chronic bronchitis and severe COPD, especially in those who had hospitalizations for acute COPD exacerbations in the previous year. ${ }^{54,55}$ The patient should be monitored for side effects including diarrhea, nausea, decreased appetite, weight loss, abdominal pain, and sleep disturbance. Roflumilast should be avoided in underweight patients and used with caution in patients with depression. ${ }^{56}$

\section{Antibiotics}

Long-term treatment with azithromycin reduces number of exacerbations and improves quality of life in patients at risk of exacerbations. ${ }^{57}$ This treatment should also be considered in patients with concomitant bronchiectasis and neutrophilic-type exacerbations. ${ }^{58}$ Multiple regimens are used including $250 \mathrm{mg}$ /day or $250-500 \mathrm{mg}$ three times per week, but there are no data on effectiveness beyond 1 year. ${ }^{59}$ Long-term treatment is associated with increased incidence of colonization with macrolide-resistant organisms, QT prolongation, and hearing impairment. ${ }^{57,59}$ Prior to initiation of the therapy, baseline investigation should include acid-fast bacillus testing, liver function test (LFT), and an electrocardiogram. In case of atypical mycobacterial infection, double increase in LFT, tinnitus or hearing loss, the treatment should be stopped.

\section{$\mathrm{N}$-acetylcysteine}

In patients who continue to exacerbate despite adequate treatment, high-dose $\mathrm{N}$-acetylcysteine $(\geq 1200 \mathrm{mg})$ may be added, particularly in high-risk patients. ${ }^{60,61}$

Patients with marked exertional dyspnea despite optimal pharmacological treatment should be evaluated in a specialist center and considered for lung volume reduction surgery, long-term oxygen therapy (LTOT) or non-invasive mechanical ventilation (NIV).

\section{LTOT and NIV}

LTOT improves survival, pulmonary hemodynamics, and the quality of life in hypoxemic COPD patients and should be offered to patients with resting $\mathrm{PaO} 2 \leq 7.3 \mathrm{kPa}$ ( $\leq 55 \mathrm{mmHg}$ ) or $\mathrm{SaO} 2 \leq 88 \%$; or $\mathrm{PaO} 2$ between $7.3 \mathrm{kPa}$ $(55 \mathrm{mmHg})$ and $8.0 \mathrm{kPa}(60 \mathrm{mmHg})$ or $\mathrm{SaO} 2$ of $89 \%$, with: signs of pulmonary hypertension, peripheral edema indicating congestive heart failure or polycythemia (hematocrit $>0.55){ }^{15,19}$ It is mandatory that the patient does not smoke and has adequate housing conditions for installation and proper use of the appliance.

Although highly effective in acute exacerbations, the use of NIV in stable, severe COPD patients still remains controversial, and its use significantly varies between countries. ${ }^{62-64}$ So far, studies demonstrated survival benefits in hypercapnic, stable COPD when NIV was aimed at reducing $\mathrm{PaCO}_{2}{ }^{65,66}$ Following an acute exacerbation of COPD in patients with persistent hypercapnia, adding NIV to home oxygen therapy prolonged the time to readmission or death within 12 months. ${ }^{67}$ Based on these recent findings, NIV may be offered to a carefully selected group of severe, hypercapnic COPD patients. The selection, initiation, and monitoring of NIV treatment should be done in a specialized center with experience in NIV therapy. In stable COPD patients with increased daytime sleepiness or nocturnal desaturation despite the use of supplemental oxygen, assessment for obstructive sleep apnea (OSA) may identify patients with COPD-OSA overlap syndrome. In these patients, the use of nocturnal continuous positive pressure ventilation significantly improves survival and decreases the risk of severe COPD exacerbations. ${ }^{68,69}$ In COPD-OSA patients with predominant COPD or daytime hypercapnia, NIV is preferred over continuous positive airway pressure. ${ }^{68}$

Palliative and end-of-life care in patients with severe COPD

Due to high morbidity and mortality, an effort should be made to optimize palliative care to relieve suffering and 
improve quality of life of patients and their families. Where available, a palliative care team should be consulted for symptom management in severe COPD patients with marked breathlessness, anxiety or fatigue. ${ }^{19}$ Specialized outpatient settings should be established, with multidisciplinary teams applying various palliative treatments (pulmonary rehabilitation, short-acting opioids for intractable cough and dyspnea, treatment of comorbidities, psychological and psychiatric counseling, self-care management planning, social worker support, etc). ${ }^{70}$ Although predicting mortality in COPD is challenging, in severe COPD patients one or more of the following characteristics may be considered as a trigger for end-of-life preferences discussion: $\mathrm{FEV}_{1}<30 \%$, oxygen dependence, repeated hospital admissions in the previous year for an acute exacerbation of COPD, significant comorbidities, cachexia, increasing dependence on others, older age or high BODE (body mass index, airflow obstruction, dyspnea and exercise capacity)Index. ${ }^{71,72}$

\section{ACO}

Diagnosis of asthma or COPD should be based on detailed history and functional evaluation. ACO should be considered in patients with clinical features of both diseases. ${ }^{32,73}$ For the diagnosis, the postbronchodilator $\mathrm{FEV}_{1} / \mathrm{FVC}$ ratio should be $<70 \%$ or LLN. Identification of patients with overlap is important as these patients have worse prognosis compared to patients who have only asthma or COPD. $^{32}$ ACO should be considered in patients with asthma who have decreased lung diffusion capacity for carbon monoxide or computed tomography evidence of emphysema, and in patients with COPD who have significant airway obstruction reversibility or eosinophilia (Figure 2). ${ }^{9}$ Lung diffusion capacity should be measured in stable condition, outside COPD exacerbations. The therapy should consist of ICS and bronchodilators.

\section{Patient follow-up}

The patients should initially be monitored 1 month after initiation of the therapy, additional follow-up should take place at 3-6 months in high-risk and 6-12 months in low-risk patients. Drug effectiveness and inhaler use should be assessed at each visit and adjusted if needed.

\section{De-escalation of ICS}

Up to $80 \%$ of all COPD patients and $50 \%$ of non-exacerbators in Serbia receive ICS in combination with LABA or in the form of triple therapy. ${ }^{7}$ In many of these patients
ICS are not effective and may be associated with adverse outcomes including pneumonia, decreased bone density/ fractures, cataract, and mycobacterial infections. In this document, special consideration has been given to deescalation of ICS from triple therapy based on available evidence. Despite the fact that evidence for de-escalation from LABA/ICS is not available, we recommend withdrawal of ICS in patients on LABA/ICS based on clinical judgment, in case of inappropriate original indication, pneumonia or other ICS-related side effects (Figure 3).

Low-risk patients: we recommend de-escalation of ICS in low-risk, non-exacerbating patients with eosinophil count $<300 / \mu \mathrm{L}$.

The abrupt de-escalation of ICS has recently been shown to be safe in non-exacerbating ( $\leq 1$ exacerbations) low-risk $\left(\mathrm{FEV}_{1}>40 \%\right)$ patients with eosinophil count $<300 / \mu \mathrm{L}$. ICS withdrawal was related to a small decrease in lung function of $26 \mathrm{~mL}$. $^{42}$ Safety of ICS withdrawal in low-risk, non-frequent exacerbators has also been previously shown in a real-life study. ${ }^{74}$

High-risk patients: we recommend de-escalation of ICS in high-risk patients with eosinophil count $<300 / \mu \mathrm{L}$ in case of pneumonia or other ICS side effects. The deescalation should be done gradually by reducing ICS dose every 6 weeks, under a pulmonologist's supervision with close follow-up.

In patients receiving triple therapy with $\mathrm{FEV}_{1}<50 \%$ and at least one exacerbation/year, gradual tapering of ICS over 12 weeks was not associated with increased exacerbation risk, but led to a modest reduction of $\mathrm{FEV}_{1}$ of $38 \mathrm{~mL}{ }^{43}$ A post hoc analysis revealed increased risk of

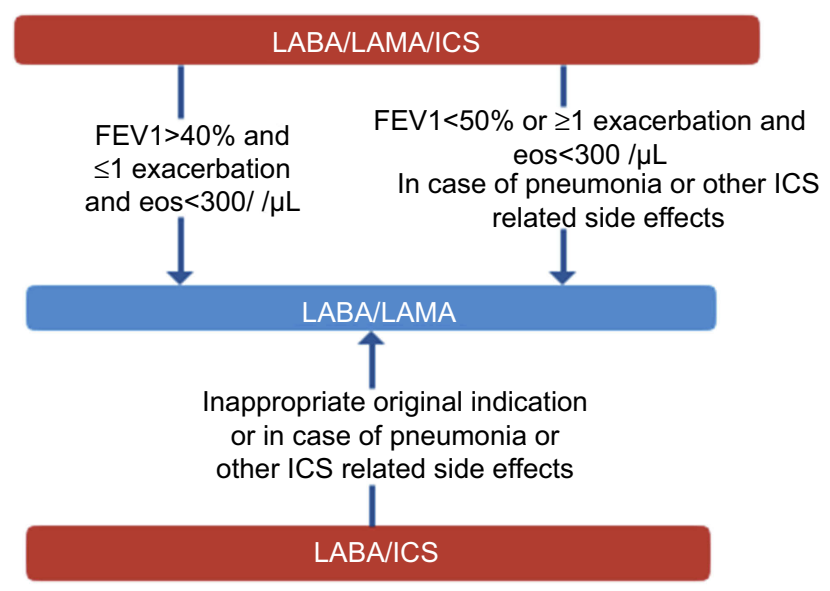

Figure 3 De-escalation of ICS in COPD.

Abbreviations: ICS, inhaled corticosteroids; LABA, long-acting beta ${ }_{2}$-agonist; LAMA, long-acting muscarinic antagonist. 
exacerbations in patients with eosinophils $>2 \%$ with a significant treatment-by-subgroup interaction in patients with eosinophil count of $4 \%$ or $300 / \mu \mathrm{L} .{ }^{46}$ As number of previous exacerbations is the strongest predictor of future exacerbations, ${ }^{47}$ we recommend ICS withdrawal in highrisk patients based on individual assessment of risk-benefit ratio. Patients with eosinophil count $<100 / \mu \mathrm{L}$ are not likely to benefit from ICS. ${ }^{34}$

We recommend ICS withdrawal outside winter months due to seasonal variations of COPD exacerbations. The exacerbation hazard is 2-fold higher during winter compared to summer months and respiratory deaths peak in early spring. ${ }^{75}$ Dose tapering can be done abruptly in low-risk patients or every 6 weeks (total 12 weeks) in high-risk patients. Since the risk of exacerbations is highest in the first weeks following ICS withdrawal, we recommend monthly follow-up after each ICS dose is tapered until complete cessation. Additional monitoring should be performed after 3 months, and then on a regular basis.

\section{Inhaler choice}

Deciding on an inhaler should be done on an individual basis, taking into account the patient's ability and preferences. Patients with poor coordination should not be prescribed a metered dose inhaler (MDI) unless a spacer is used, and patients with low inspiratory flow should not be prescribed a dry powder inhaler (DPI). Use of a single inhaler device is preferred. All patients should be educated on how to use the inhaler and the technique should be checked at each visit.

Currently, three major types of inhalers are available: MDI, DPI, and soft mist inhaler (SMI). The choice of inhaler is determined by drug availability and the ability of the patient to use the inhaler device correctly. ${ }^{76} \mathrm{Up}$ to two thirds of patients make at least one critical mistake that significantly decreases lung deposition. ${ }^{77}$ Critical mistakes are associated with exacerbations and increased health care utilization. ${ }^{78,79}$ Common critical mistakes are lack of coordination and drug activation for MDIs and insufficient inspiration flow for DPIs. ${ }^{80}$ SMI does not require forceful inspiration and is less dependent on coordination, but a failure in dose preparation may occur. ${ }^{81}$ The choice of inhaler is individual, as critical mistakes can happen with any inhaler. Although many patients will be able to use any of these devices, the assessment of coordination and inspiratory flow should be done initially to avoid non-adherence related to ineffectiveness, and re- checked in case of treatment failure. The assessment of coordination and inspiration flow is usually based on clinical judgment. Coordination is more likely to be impaired in the elderly and patients with comorbidities such as neurological or joint diseases. In case of poor coordination, we recommend use of an MDI with spacer, DPI or SMI. Both DPIs and SMIs are considered to be simple, easy to use, and are well-perceived by the patient. ${ }^{76,82,83}$ Insufficient respiratory flow should be particularly considered in elderly, severe COPD, and patients with muscle wasting. Objective assessment of peak inspiratory flow may be done with the use of In-Check dial devices, but these are not readily available. The minimal inspiratory flow (necessary to detach the drug from the carrier) and optimal flow (allows optimal lung deposition) are specific for each inhaler, depending on resistance of the device. In general, respiratory flow $>60 \mathrm{~L} / \mathrm{min}$ is considered adequate. $^{76,84,85}$ The use of spirometry indices in assessing inspiratory flow has not been adequately addressed. In case of poor inspiratory flow, MDI or SMI should be prescribed. Use of multiple inhalers which require different inhalation techniques are also associated with increased risk of exacerbations and rescue medication use, ${ }^{86}$ thus, drug combinations in a single inhaler device should be prescribed whenever possible. After selection of an appropriate inhaler, the inhalation technique should be demonstrated using the teach-back method, and rechecked at every visit. ${ }^{87}$

\section{Conclusion}

In conclusion, we presented an expert position statement for COPD treatment in Serbia. This statement reflects the current GOLD strategy to some extent but is tailored according to local epidemiological situation and practice. It also favors risk stratification using lung function and dyspnea and early phenotypization using medical history, blood eosinophils, and number of exacerbations. A simple one-page initial and step-up therapy algorithm is provided considering busy outpatient clinics. Besides treatment strategies for pharmacological treatment, equal importance is given to early detection, non-pharmacological measures, step-down therapy, and inhaler choice. With such approach, we aim to initiate treatment in early stages, improve cost-effectiveness, reduce possible side effects, and ensure efficient treatment. With respect to future research, national registry data can be used to evaluate the effects of proposed algorithms on a national level, including adherence to recommendations, assessment of obstacles and benefit-risk ratios. 


\section{Acknowledgment}

The authors wish to thank the following respiratory specialists for their valuable feedback:

Miroslav Ilic, Mihailo Stjepanovic, Rade Milic, Djordje Tausan, Ivana Nikolic-Brstina, Aleksandra Zdravkovic-Mihajlovic, Ivana Mikavica, Dejan Zujovic, Vesna Dopudja-Pantic, Vojislav Cupurdija, Saša Jovanović, Valentin Petrov, Slobodan Petrovic, and Danijela Kuhajda.

\section{Disclosure}

MV has received honoraria for scientific advice and/or for lecturing from Boehringer Ingelheim, GlaxoSmithKline, and Novartis, outside the submitted work. IK has received honoraria for scientific advice and/or for lecturing from AstraZeneca, GlaxoSmithKline, Novartis, Boehringer Ingelheim, Teva, Chiesi, Menarini, outside the submitted work. ZL has received honoraria for lecturing from AstraZeneca, Boehringer Ingelheim, GlaxoSmithKline, Novartis, Teva, Chiesi, outside the submitted work. BZ has received honoraria for scientific advice and/or for lecturing from AstraZeneca, Glaxo SmithKline, Novartis, Boehringer Ingelheim, Chiesi, Menarini, outside the submitted work. ADI has received honoraria for scientific advice and/or lecturing from AstraZeneca, Boehringer Ingelheim, GlaxoSmithKline, Novartis, outside the submitted work. IC has received honoraria for lecturing from AstraZeneca, Boehringer Ingelheim, GlaxoSmithKline, Novartis, outside the submitted work. MV has received honoraria for scientific advice and/or for lecturing from AstraZeneca, Glaxo SmithKline, Novartis, Boehringer Ingelheim, Teva, Chiesi outside the submitted work. VZ has received honoraria for scientific advice and/or for lecturing from AstraZeneca, Boehringer Ingelheim, GlaxoSmithKline, Teva, Chiesi, Novartis, outside the submitted work. SH has received honoraria for scientific advice and/or for lecturing from AstraZeneca, Boehringer Ingelheim, GlaxoSmithKline, Teva, Chiesi, Novartis, outside the submitted work. The authors report no other conflicts of interest in this work.

\section{References}

1. Adeloye D, Chua S, Lee C, et al. Global and regional estimates of COPD prevalence: systematic review and meta-analysis. $J$ Glob Health. 2015;5:020415. doi:10.7189/jogh.05.020415

2. Mortality GBD, Causes of Death C. Global, regional, and national agesex specific all-cause and cause-specific mortality for 240 causes of death, 1990-2013: a systematic analysis for the Global Burden of Disease Study 2013. Lancet. 2015;385:117-171. doi:10.1016/S01406736(14)61682-2

3. Boricic K, Vasic M, Grozdanov J, et al. Results of the National Health Survey of the Republic of Serbia 2013. Belgrade: Institute of Public Health of Serbia, 2014. Available from: http://www.batut.org.rs/download/publika cije/2013SerbiaHealthSurvey.pdf. Accessed August 08, 2019
4. Vukoja M, Rebic P, Lazic Z, et al. Early detection of asthma and chronic obstructive pulmonary disease in primary care patients. Med Pregl. 2013;66:46-52.

5. Milenkovic B, Mitic-Milikic M, Rebic P, et al. Asthma and chronic bronchitis symptoms among adult population of Belgrade. Srp Arh Celok Lek. 2011;139:149-154.

6. Koblizek V, Milenkovic B, Barczyk A, et al. Phenotypes of COPD patients with a smoking history in Central and Eastern Europe: the POPE study. Eur Respir J. 2017;49:1601446.

7. Lazic Z, et al. Serbian National COPD Registry. Unpublished data

8. Aisanov Z, Avdeev S, Arkhipov V, et al. Russian guidelines for the management of COPD: algorithm of pharmacologic treatment. Int $J$ Chron Obstruct Pulmon Dis. 2018;13:183-187. doi:10.2147/COPD. S153770

9. Miravitlles M, Soler-Cataluna JJ, Calle M, et al. Spanish guidelines for management of chronic obstructive pulmonary disease (GesEPOC) 2017. Pharmacological treatment of stable phase. Arch Bronconeumol. 2017;53:324-335. doi:10.1016/j.arbres.2017.03.018

10. Koblizek V, Chlumsky J, Zindr V, et al. Chronic Obstructive Pulmonary Disease: official diagnosis and treatment guidelines of the Czech Pneumological and Phthisiological Society; a novel phenotypic approach to COPD with patient-oriented care. Biomed Pap Med Fac Univ Palacky Olomouc Czech Repub. 2013;157:189-201. doi:10.5507/bp.2013.039

11. Khan JH, Lababidi HM, Al-Moamary MS, et al. The Saudi guidelines for the diagnosis and management of COPD. Ann Thorac Med. 2014;9:55-76. doi:10.4103/1817-1737.128843

12. Bourbeau J, Bhutani M, Hernandez P, et al. CTS position statement: Pharmacotherapy in patients with COPD - An update. Canadian $J$ Respir Crit Care Sleep Med. 2017;1(4):222-241.

13. Zysman M, Chabot F, Housset B, et al, Société de Pneumologie de Langue Française. Pharmacological treatment optimisation for stable COPD: an endless story? Proposals from the Société de Pneumologie de Langue Française. Eur Respir J. 2017;50(4):1701250.

14. Registar pacijenata sa hroničnom opstruktivnom bolešću pluća; 2019. Available from http://www.hobp.rs/login.php?lan=0. Accessed August 08, 2019.

15. Mitic-Milikic M, Vukcevic M, Zvezdin B et al. Nacionalni vodič dobre kliničke prakse za dijagnostiku i lečenja hronične opstruktivne bolesti pluća; 2012.Ministarstvo zdravlja Republike Srbije. Available from: http://www.batut.org.rs/download/aktuelno/klinicka\%20praksa/ Hronicna\%20opstruktivna\%20bolest \%20pluca.pdf. Accessed August 08, 2019.

16. Jovanovic V, Ivanovic I, Krstic M, et al. Health Statistical Yearbook Of Republic Of Serbia 2017. Belgrade: Institute of Public Health of Serbia, 2018. Available from http://www.batut.org.rs/download/publi kacije/pub2017v026.pdf. Accessed August 08, 2019.

17. Miller MR, Hankinson J, Brusasco V, et al. Standardisation of spirometry. Eur Respir J. 2005;26:319-338. doi:10.1183/09031936.05. 00034805

18. Vukoja M, Bokan A, Vujasinovic G, et al. The differences in spirometry predictive equations in classifying presence and degree of lung function impairment: which suit fits the best? Lung. 2018;196:87-92. doi:10.1007/s00408-017-0065-7

19. From the Global Strategy for the Diagnosis, Management and Prevention of COPD, Global Initiative for Chronic Obstructive Lung Disease (GOLD)-2019 Report; 2019 Available from: https:// goldcopd.org/. Accessed August 08, 2019.

20. World Health Organization. Chronic obstructive pulmonary disease (COPD) 2017. Available from: https://www.who.int/news-room/factsheets/detail/chronic-obstructive-pulmonary-disease-(copd). Accessed August 08, 2019.

21. Poole PJ, Chacko E, Wood-Baker RW, et al. Influenza vaccine for patients with chronic obstructive pulmonary disease. Cochrane Database Syst Rev. 2006 (1);CD002733. 
22. Kopsaftis Z, Wood-Baker R, Poole P. Influenza vaccine for chronic obstructive pulmonary disease (COPD). Cochrane Database Syst Rev. 2018;6:CD002733.

23. Tomczyk S, Bennett NM, Stoecker C, et al. Use of 13-valent pneumococcal conjugate vaccine and 23-valent pneumococcal polysaccharide vaccine among adults aged $>/=65$ years: recommendations of the Advisory Committee on Immunization Practices (ACIP). MMWR Morb Mortal Wkly Rep. 2014;63:822-825.

24. McCarthy B, Casey D, Devane D, et al. Pulmonary rehabilitation for chronic obstructive pulmonary disease. Cochrane Database Syst Rev 2015;2:CD003793.

25. Vogiatzis I, Rochester CL, Spruit MA, et al. Increasing implementation and delivery of pulmonary rehabilitation: key messages from the new ATS/ERS policy statement. Eur Respir J. 2016;47:1336-1341. doi:10.1183/13993003.02151-2015

26. Faulkner MA, Lenz TL, Stading JA. Cost-effectiveness of smoking cessation and the implications for COPD. Int $J$ Chron Obstruct Pulmon Dis. 2006;1:279-287.

27. Lall D, Cason E, Pasquel FJ, et al. Effectiveness of influenza vaccination for individuals with chronic obstructive pulmonary disease (COPD) in Low- and middle-income countries. COPD. 2016;13:93-99. doi:10.3109/15412555.2015.1043518

28. Ilic M. Frequency and effects of seasonal flu vaccines on exacerbations of chronic obstructive pulmonary disease in Serbia. Mil Med Pharm J Serb. 2019;49. doi:10.2298/VSP181214049I

29. Zhou Y, Zhong NS, Li X, et al. Tiotropium in early-stage chronic obstructive pulmonary disease. $N$ Engl J Med. 2017;377:923-935. doi:10.1056/NEJMoa1700228

30. Vogelmeier C, Hederer B, Glaab T, et al. Tiotropium versus salmeterol for the prevention of exacerbations of COPD. $N$ Engl J Med. 2011;364:1093-1103. doi:10.1056/NEJMoa1008378

31. Decramer ML, Chapman KR, Dahl R, et al. Once-daily indacaterol versus tiotropium for patients with severe chronic obstructive pulmonary disease (INVIGORATE): a randomised, blinded, parallelgroup study. Lancet Respir Med. 2013;1:524-533. doi:10.1016/ S2213-2600(13)70158-9

32. The Global Strategy for the Diagnosis, Management and Prevention of COPD.Asthma, COPD, and asthma-COPD overlap syndrome; 2015. Available from: https://goldcopd.org/asthma-copd-asthmacopd-overlap-syndrome/

33. Leung JM, Sin DD. Inhaled corticosteroids in COPD: the final verdict is. Eur Respir J. 2018;52:1801940.

34. Bafadhel M, McKenna S, Terry S, et al. Blood eosinophils to direct corticosteroid treatment of exacerbations of chronic obstructive pulmonary disease: a randomized placebo-controlled trial. Am J Respir Crit Care Med. 2012;186:48-55. doi:10.1164/rccm.201108-1553OC

35. Hamad GA, Cheung W, Crooks MG, et al. Eosinophils in COPD: how many swallows make a summer? Eur Respir J. 2018;51:1702177.

36. Greulich T, Mager S, Lucke T, et al. Longitudinal stability of blood eosinophil count strata in the COPD COSYCONET cohort. Int J Chron Obstruct Pulmon Dis. 2018;13:2999-3002. doi:10.2147/COPD.S165909

37. Calzetta L, Rogliani P, Matera MG, et al. A systematic review with meta-analysis of dual bronchodilation with LAMA/LABA for the treatment of stable COPD. Chest. 2016;149:1181-1196. doi:10.10 16/j.chest.2016.02.646

38. Vukoja M, Kopitovic I, Milicic D, et al. Sleep quality and daytime sleepiness in patients with COPD and asthma. Clin Respir J. 2018;12:398-403. doi:10.1111/crj.12528

39. Zvezdin B, Milutinov S, Kojicic M, et al. A postmortem analysis of major causes of early death in patients hospitalized with COPD exacerbation. Chest. 2009;136:376-380. doi:10.1378/chest.08-2918

40. Pavord ID, Lettis S, Anzueto A, et al. Blood eosinophil count and pneumonia risk in patients with chronic obstructive pulmonary disease: a patient-level meta-analysis. Lancet Respir Med. 2016;4:731741. doi:10.1016/S2213-2600(16)30148-5
41. Papi A, Vestbo J, Fabbri L, et al. Extrafine inhaled triple therapy versus dual bronchodilator therapy in chronic obstructive pulmonary disease (TRIBUTE): a double-blind, parallel group, randomised controlled trial. Lancet. 2018;391:1076-1084. doi:10.1016/S0140-6736(18)30206-X

42. Chapman KR, Hurst JR, Frent SM, et al. Long-term triple therapy deescalation to Indacaterol/Glycopyrronium in patients with chronic obstructive pulmonary disease (SUNSET): a randomized, doubleblind, triple-dummy clinical trial. Am J Respir Crit Care Med. 2018;198:329-339. doi:10.1164/rccm.201803-0405OC

43. Magnussen H, Disse B, Rodriguez-Roisin R, et al. Withdrawal of inhaled glucocorticoids and exacerbations of COPD. $N$ Engl J Med. 2014;371:1285-1294. doi:10.1056/NEJMoa1407154

44. Vestbo J, Papi A, Corradi M, et al. Single inhaler extrafine triple therapy versus long-acting muscarinic antagonist therapy for chronic obstructive pulmonary disease (TRINITY): a double-blind, parallel group, randomised controlled trial. Lancet. 2017;389:1919-1929. doi:10.1016/S0140-6736(17)30188-5

45. Siddiqui SH, Guasconi A, Vestbo J, et al. Blood eosinophils: a biomarker of response to extrafine Beclomethasone/Formoterol in chronic obstructive pulmonary disease. Am J Respir Crit Care Med. 2015;192:523-525. doi:10.1164/rccm.201502-0235LE

46. Watz H, Tetzlaff K, Wouters EF, et al. Blood eosinophil count and exacerbations in severe chronic obstructive pulmonary disease after withdrawal of inhaled corticosteroids: a post-hoc analysis of the WISDOM trial. Lancet Respir Med. 2016;4:390-398. doi:10.1016/ S2213-2600(16)00100-4

47. Hurst JR, Vestbo J, Anzueto A, et al. Susceptibility to exacerbation in chronic obstructive pulmonary disease. $N$ Engl J Med. 2010;363:1128-1138. doi:10.1056/NEJMoa0909883

48. Calverley PMA, Tetzlaff K, Vogelmeier C, et al. Eosinophilia, frequent exacerbations, and steroid response in chronic obstructive pulmonary disease. Am J Respir Crit Care Med. 2017;196:12191221. doi:10.1164/rccm.201612-2525LE

49. Lipson DA, Barnhart F, Brealey N, et al. Once-daily single-inhaler triple versus dual therapy in patients with COPD. $N$ Engl J Med. 2018;378:1671-1680. doi:10.1056/NEJMoa1713901

50. Singh D, Papi A, Corradi M, et al. Single inhaler triple therapy versus inhaled corticosteroid plus long-acting beta2-agonist therapy for chronic obstructive pulmonary disease (TRILOGY): a double-blind, parallel group, randomised controlled trial. Lancet. 2016;388:963973. doi:10.1016/S0140-6736(16)31354-X

51. Jones PW, Beeh KM, Chapman KR, et al. Minimal clinically important differences in pharmacological trials. Am J Respir Crit Care Med. 2014;189:250-255. doi:10.1164/rccm.201310-1863PP

52. Hohlfeld JM, Vogel-Claussen J, Biller H, et al. Effect of lung deflation with indacaterol plus glycopyrronium on ventricular filling in patients with hyperinflation and COPD (CLAIM): a double-blind, randomised, crossover, placebo-controlled, single-centre trial. Lancet Respir Med. 2018;6:368-378. doi:10.1016/S2213-2600(18)30054-7

53. O'Donnell DE, Casaburi R, Frith P, et al. Effects of combined tiotropium/olodaterol on inspiratory capacity and exercise endurance in COPD. Eur Respir J. 2017;49:1601348.

54. Rabe KF, Calverley PMA, Martinez FJ, et al. Effect of roflumilast in patients with severe COPD and a history of hospitalisation. Eur Respir J. 2017;50:1700158.

55. Martinez FJ, Calverley PM, Goehring UM, et al. Effect of roflumilast on exacerbations in patients with severe chronic obstructive pulmonary disease uncontrolled by combination therapy (REACT): a multicentre randomised controlled trial. Lancet. 2015;385:857-866. doi:10.1016/S0140-6736(14)62410-7

56. Chong J, Leung B, Poole P. Phosphodiesterase 4 inhibitors for chronic obstructive pulmonary disease. Cochrane Database Syst Rev. 2017;9:CD002309.

57. Albert RK, Connett J, Bailey WC, et al. Azithromycin for prevention of exacerbations of COPD. N Engl J Med. 2011;365:689-698. doi:10.1056/NEJMoa1104623 
58. Kelly C, Chalmers JD, Crossingham I, et al. Macrolide antibiotics for bronchiectasis. Cochrane Database Syst Rev. 2018;3:CD012406.

59. Herath SC, Normansell R, Maisey S, et al. Prophylactic antibiotic therapy for chronic obstructive pulmonary disease (COPD). Cochrane Database Syst Rev. 2018;10:CD009764.

60. Poole P, Chong J, Cates CJ. Mucolytic agents versus placebo for chronic bronchitis or chronic obstructive pulmonary disease. Cochrane Database Syst Rev. 2015;5;CD001287.

61. Zheng JP, Wen FQ, Bai CX, et al. Twice daily N-acetylcysteine $600 \mathrm{mg}$ for exacerbations of chronic obstructive pulmonary disease (PANTHEON): a randomised, double-blind placebo-controlled trial. Lancet Respir Med. 2014;2:187-194. doi:10.1016/S2213-2600(13)70286-8

62. Struik FM, Lacasse Y, Goldstein R, et al. Nocturnal non-invasive positive pressure ventilation for stable chronic obstructive pulmonary disease. Cochrane Database Syst Rev. 2013;6:CD002878.

63. Crimi C, Noto A, Princi $P$, et al. Domiciliary non-invasive ventilation in COPD: an international survey of indications and practices. COPD. 2016;13:483-490. doi:10.3109/15412555.2015.1108960

64. Duiverman ML. Noninvasive ventilation in stable hypercapnic COPD: what is the evidence? ERJ Open Res. 2018;4:00012-2018. doi:10.1183/23120541.00012-2018

65. Kohnlein T, Windisch W, Kohler D, et al. Non-invasive positive pressure ventilation for the treatment of severe stable chronic obstructive pulmonary disease: a prospective, multicentre, randomised, controlled clinical trial. Lancet Respir Med. 2014;2:698-705. doi:10.1016/S2213-2600(14)70153-5

66. Liao H, Pei W, Li H, et al. Efficacy of long-term noninvasive positive pressure ventilation in stable hypercapnic COPD patients with respiratory failure: a meta-analysis of randomized controlled trials. Int J Chron Obstruct Pulmon Dis. 2017;12:2977-2985. doi:10.2147/ COPD.S148422

67. Murphy PB, Rehal S, Arbane G, et al. Effect of home noninvasive ventilation with oxygen therapy vs oxygen therapy alone on hospital readmission or death after an acute COPD exacerbation: a randomized clinical trial. JAMA. 2017;317:2177-2186. doi:10.1001/ jama.2017.4451

68. McNicholas WT. COPD-OSA overlap syndrome: evolving evidence regarding epidemiology, clinical consequences, and management. Chest. 2017;152:1318-1326. doi:10.1016/j.chest.2017.04.160

69. Marin JM, Soriano JB, Carrizo SJ, et al. Outcomes in patients with chronic obstructive pulmonary disease and obstructive sleep apnea: the overlap syndrome. Am J Respir Crit Care Med. 2010;182:325331. doi:10.1164/rccm.200912-18690C

70. Vermylen JH, Szmuilowicz E, Ravi Kalhan R. Palliative care in COPD: an unmet area for quality improvement. Int J Chron Obstruct Pulmon Dis. 2015;10:1543-1551. doi:10.2147/COPD.S74641

71. Curtis JR. Palliative and end-of-life care for patients with severe COPD. Eur Respir J. 2008;32:796-803. doi:10.1183/09031936.00126107

72. Smith LE, Moore E, Ali I, et al. Prognostic variables and scores identifying the end of life in COPD: a systematic review. Int J Chron Obstruct Pulmon Dis. 2017;12:2239-2256. doi:10.2147/COPD.S13 7868
73. Barnes PJ. Asthma-COPD Overlap. Chest. 2016;149:7-8. doi:10.1016/j.chest.2015.08.017

74. Rossi A, Guerriero M, Corrado A, et al. Withdrawal of inhaled corticosteroids can be safe in COPD patients at low risk of exacerbation: a real-life study on the appropriateness of treatment in moderate COPD patients (OPTIMO). Respir Res. 2014;15:77. doi:10.11 86/1465-9921-15-77

75. Wise RA, Calverley PM, Carter K, et al. Seasonal variations in exacerbations and deaths in patients with COPD during the TIOSPIR((R)) trial. Int $J$ Chron Obstruct Pulmon Dis. 2018;13:605-616. doi:10.2147/COPD.S148393

76. Laube BL, Janssens HM, de Jongh FH, et al. What the pulmonary specialist should know about the new inhalation therapies. Eur Respir J. 2011;37:1308-1331. doi:10.1183/09031936.00166410

77. Chrystyn H, van der Palen J, Sharma R, et al. Device errors in asthma and COPD: systematic literature review and meta-analysis. NPJ Prim Care Respir Med. 2017;27:22. doi:10.1038/s41533-017-0016-Z

78. Usmani OS, Lavorini F, Marshall J, et al. Critical inhaler errors in asthma and COPD: a systematic review of impact on health outcomes. Respir Res. 2018;19:10. doi:10.1186/s12931-017-0710-y

79. Melani AS, Bonavia M, Cilenti V, et al. Inhaler mishandling remains common in real life and is associated with reduced disease control. Respir Med. 2011;105:930-938. doi:10.1016/j.rmed.2011.01.005

80. Sanchis J, Gich I, Pedersen S, et al. Systematic review of errors in inhaler use: has patient technique improved over time? Chest. 2016;150:394-406. doi:10.1016/j.chest.2016.03.041

81. Molimard M, Raherison C, Lignot S, et al. Chronic obstructive pulmonary disease exacerbation and inhaler device handling: reallife assessment of 2935 patients. Eur Respir J. 2017;49:1601794.

82. Dudvarski Ilic A, Zugic V, Zvezdin B, et al. Influence of inhaler technique on asthma and COPD control: a multicenter experience. Int J Chron Obstruct Pulmon Dis. 2016;11:2509-2517.

83. Miravitlles M, Montero-Caballero J, Richard F, et al. A cross-sectional study to assess inhalation device handling and patient satisfaction in COPD. Int J Chron Obstruct Pulmon Dis. 2016;11:407-415. doi:10.2147/COPD.S91118

84. Haidl P, Heindl S, Siemon K, et al. Inhalation device requirements for patients' inhalation maneuvers. Respir Med. 2016;118:65-75. doi:10.1016/j.rmed.2016.07.013

85. Mahler DA. Peak inspiratory flow rate as a criterion for dry powder inhaler use in chronic obstructive pulmonary disease. Ann Am Thorac Soc. 2017;14:1103-1107. doi:10.1513/AnnalsATS.201702-156PS

86. Bosnic-Anticevich S, Chrystyn H, Costello RW, et al. The use of multiple respiratory inhalers requiring different inhalation techniques has an adverse effect on COPD outcomes. Int J Chron Obstruct Pulmon Dis. 2017;12:59-71. doi:10.2147/COPD.S117196

87. Dantic DE. A critical review of the effectiveness of 'teach-back' technique in teaching COPD patients self-management using respiratory inhalers. Health Educ J. 2014;73:41-50. doi:10.1177/00178969 12469575

\section{Publish your work in this journal}

The International Journal of COPD is an international, peer-reviewed journal of therapeutics and pharmacology focusing on concise rapid reporting of clinical studies and reviews in COPD. Special focus is given to the pathophysiological processes underlying the disease, intervention programs, patient focused education, and self management protocols. This journal is indexed on PubMed Central, MedLine and CAS. The manuscript management system is completely online and includes a very quick and fair peer-review system, which is all easy to use. Visit http://www.dovepress.com/testimonials.php to read real quotes from published authors. 